\title{
Bibliometrics of ITF Coaching \& Sport Science Review
}

\author{
Duane Knudson $^{\mathrm{a}}$ \\ ${ }^{\mathrm{a}}$ Texas State University, United States of America.
}

\section{ABSTRACT}

This study documented the citation metrics of articles published by the ITF Coaching \& Sport Science Review (ITFCSSR) and indexed in Google Scholar (GS). A systematic searching of GS returned 209 unique ITFCSSR indexed articles published between 1993 and 2019 with 1139 citations. ITFCSSR articles had relatively low citation rates that confirmed previous bibliometric research on the gradual development of tennis knowledge compared to faster moving biomedical fields. ITFCSSR articles may make unique contributions to knowledge development in tennis science, particularly in coaching, physiology, and analytics/tactics.

\author{
Key words: Citation, index \\ infometrics, knowledge, \\ scientometrics. \\ Received: 20 September 2020 \\ Accepted: 25 October 2020 \\ Corresponding author: \\ Duane Knudson, Department \\ of Health and Human \\ Performance, Texas State \\ University, United States of \\ America. Email: \\ dknudson@txstate.edu
}

\section{INTRODUCTION}

Tennis is a popular sport world-wide so there is considerable scientific interest in the sport. Research on tennis is published in a wide variety of disciplines on many sportspecific topics (Knudson, 2012; Knudson \& Myers, 2021). There are also specialized journals in tennis science including the Journal of Medicine \& Science in Tennis (JMST) and the ITF Coaching \& Sport Science Review (ITFCSSR).

Previous tennis bibliometrics studies of tennis research has focused on highly cited articles (Knudson, 2012), ten years of Chinese research (Yuhan, 2016), and contributions from articles published in the Journal of Medicine \& Science in Tennis (Knudson \& Myers, 2020). Overall, these studies indicate stable knowledge production in tennis knowledge that may progress at a slower pace than other exercise or biomedical sciences based on citation rate to articles (Knudson \& Myers, 2020).

In 2020, the ITFCSSR marked its $28^{\text {th }}$ year with over 80 issues published in several languages. Research published in ITFCSSR contributes to tennis scientific knowledge and application of that knowledge for athletes, coaches, and sports professionals. Crespo and Over (2010) reported a content analysis the first 17 years (50 issues) of ITFCSSR and noted most articles were on psychology, coaching, and conditioning. Expansion of this initial content research to a complete bibliometric analysis of ITFCSSR could extend our understanding of knowledge development in tennis and document the unique contributions of this journal. The purpose of this study was to document the bibliometrics of articles published by the ITFCSSR and indexed in Google Scholar (GS).

\section{METHOD}

Systematic searches of the articles published by the ITFCSSR (ISSN 1812-2302 and 2225-4757) that were indexed by GS were conducted. GS provides the largest academic search engine of scholarly publication and their citations in journals, edited books, and patents. GS is also most relevant to searching for citations to ITFCSSR articles given the major subscription bibliometric databases (Scopus or Web of Science) do not index articles from the journal and are therefore provide a misleading and biased perspective on the articles published by the journal. GS indexes an estimated over 40,000 scholarly publications (Delgado-Lopez-Cozar \& Cabezas-Clavjo, 2013) at least 2 to 4 times larger than most major bibliometric databases.

The search of GS was conducted using the following strategy. Records of searches of nine variations of the name of the 
(including common wording errors) were collected. These searches and the number of returned results were:

\begin{tabular}{|l|c|}
\hline "coaching and sport science review" & 151 \\
\hline "coaching and sports science review" & 10 \\
\hline "coaching and sport sciences review" & 0 \\
\hline "ITF coaching and sport science review" & 124 \\
\hline "ITF coaching \& sport science review" & 36 \\
\hline "ITF coaching \& sport sciences review" & 0 \\
\hline "ITF coaching \& sports science review" & 5 \\
\hline "ITF coaching and sports sciences review" & 0 \\
\hline "ITF coaches" & 81 \\
\hline "ITF coaches review" & 37 \\
\hline
\end{tabular}

These results were reviewed and cleaned by examination of the title, abstracts, and if necessary, text of the articles. Duplicate records were combined and records to other publications (proceedings, books, chapter) removed. Following clean up there were 210 articles available for analysis as of July 30, 2020.

Two research usage/impact variables were collected from GS and one study variable was extracted from the articles. The usage variables were GS citations (C) to the articles and their citation rate $[C R=C /(2020$-year published $)]$. The study variable was the primary topic or main independent variable of each article. Article topic was classified into one of nine categories: Analytics/tactics, biomechanics/technique, coaching/teaching, equipment, nutrition, physiology/training, psychology/perceptual-motor, sports medicine/injury, or other (Knudson \& Myers, 2020). A previous study reported the reliability of classification of study topics was 80 to $85 \%$ agreement between two investigators. Descriptive statistical analysis of the data were performed with JMP Pro 14 (SAS Institute, Cary, NC). Data were qualitative compared to previous research and the journal's list of articles from the first 79 issues posted on the International Tennis Federation website (ITF, 2020).

\section{RESULTS}

A total of 209 unique ITFCSSR articles were indexed in GS. This represented $25 \%$ of the 846 articles published by the journal between 1993 and 2019 (ITF, 2020). The indexed articles were cited 1142 times according to GS. The distribution of citations to these articles was positively skewed $(y=2.8)$ so descriptive statistics reported in Table 1 include the median and $25^{\text {th }}$ and $75^{\text {th }}$ percentiles (interquartile range). Typical SR to indexed ITFCSSR articles were between 0.28 and 0.44 citations/year (Table 1).
Table 1. Impact/usage of articles published in ITFCSSR and indexed in Google Scholar

\begin{tabular}{llllll}
\hline Variable & Mean & SD & 25th & Median & 75th \\
\hline Citation Citations & 5.5 & 5.6 & 2.0 & 4.0 & 6.0 \\
Citation Rate & 0.44 & 0.46 & 0.15 & 0.28 & 0.58 \\
\hline
\end{tabular}

Note: Citation Rate $=$ C/(2020-year published $)$

The most common topics of indexed ITFCSSR articles were in coaching/teaching (44\%), analytics/tactics (14\%), and physiology/training (12\%) with others having smaller percentages (Figure 1). There was no apparent trend in primary topics of indexed ITFCSSR articles over the years, although coaching articles were more common early on when the journal was titled ITF Coaches Review (Figure 2).

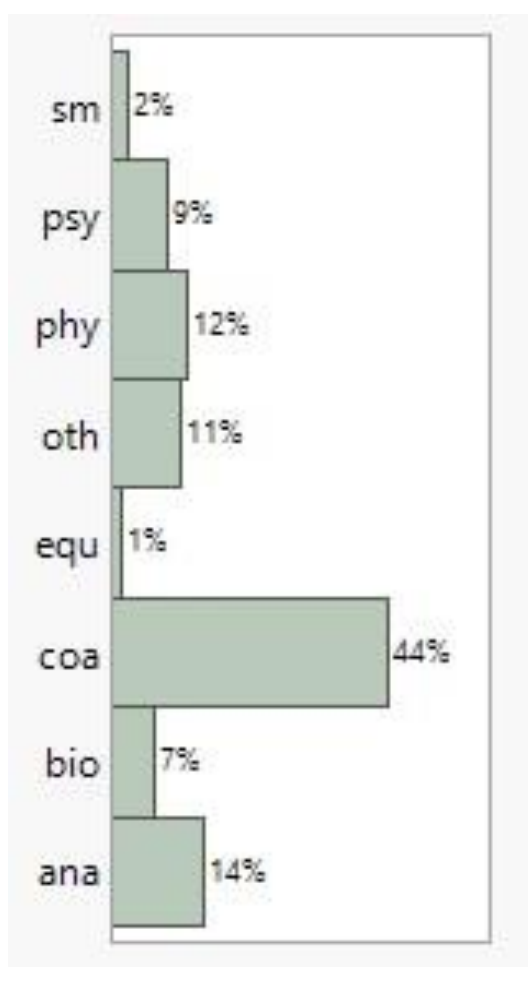




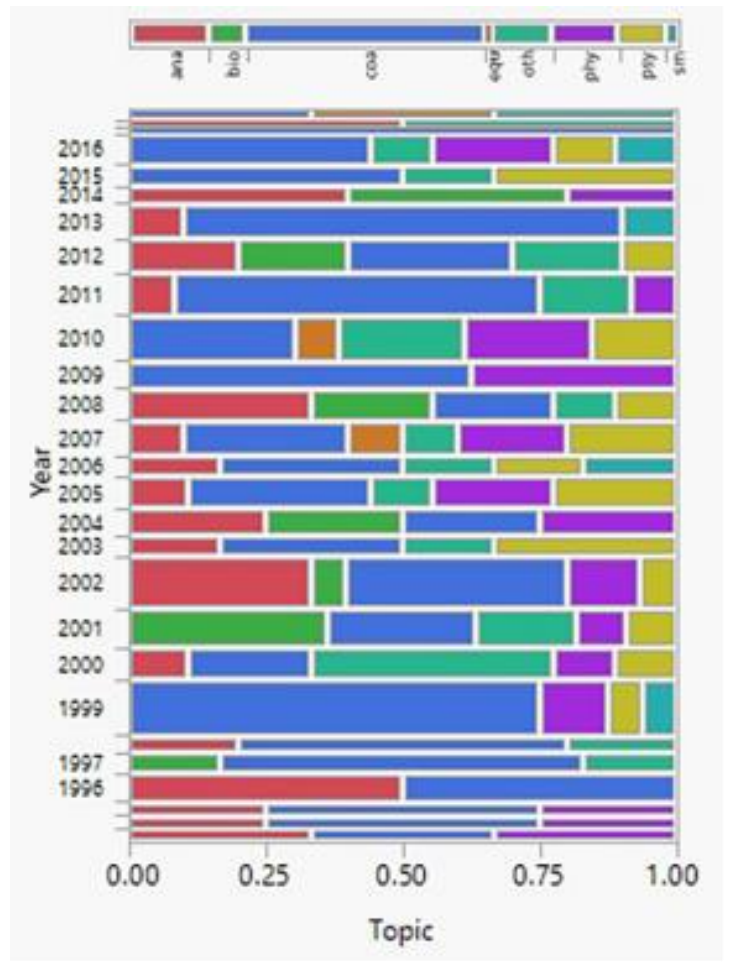

Figure 2. Distribution of primary topics of ITFCSSR articles indexed in GS by year of publication. Primary topics categories were: Analytics/tactics (ana), biomechanics/technique (bio), coaching/teaching (coa), equipment (equ), nutrition (nut), physiology/training (phy), psychology/perceptual-motor (psy), sports medicine/injury (sm), or other (oth).

\section{DISCUSSION}

Articles published in all of the first 79 issues (1993 until 2019) of ITFCSSR were indexed in GS. No articles for 2020 issues were indexed given the limited for the work to be cited. Five to 13 articles per year were typically indexed between 2000 and 2016, with fewer articles in the first eight, and fewer the last three volumes due to reduced time for citation (Figure 2histogram bar height represent numbers of records).

The majority (95\%) of the indexed articles were cited in subsequent tennis scientific research indexed by GS, although the indexed articles represented only $25 \%$ of all the articles published by the journal. The typical CR to these articles was low and about one citation over two years (Table 1). This agrees with the low CR reported for the JMST (Knudson \& Myers, 2020) and most small, specialized scientific fields (Postma, 2007). CR to articles from ITFCSSR and JMST indicate that tennis scientific knowledge may advance slower than many biomedical and exercise science fields (Owlia, Vasei, Goliaei, \& Nassiri, 2011; Knudson, 2014). Few (2-6\%) indexed articles in ITFCSSR and JMST had high citation rates (>2 C/year), however this is consistent with the results reported for even all the top cited articles in tennis science indexed in GS (Knudson, 2012).
ITFCSSR articles indexed in GS made broad contributions to tennis knowledge and were particularly strong in analytics, coaching, and physiology studies. The distribution of primary topics of indexed ITFCSSR articles (Figure 2) generally followed the distribution of article topics as identified by the journal itself (Figure 3), although the journal uses different categories. The most common topics identified by the journal were $22 \%$ (combination of coaching and teaching), miscellaneous $(16 \%)$, psychology $(12 \%)$, and conditioning (11\%). Only $7 \%$ of articles ITFCSSR classified as tactics, however a higher percentage of the indexed and cited articles (14\%) were classified in the current study as analytics/tactics.

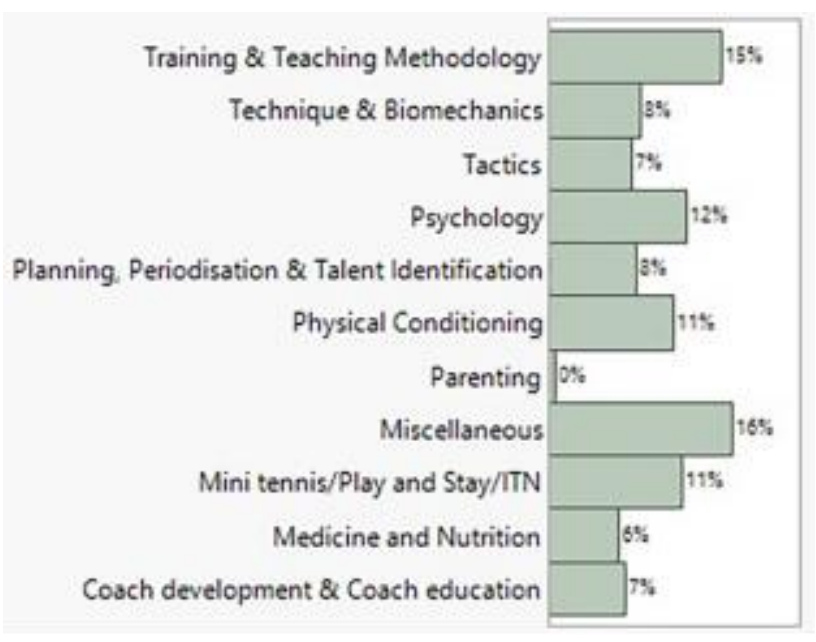

Figure 3. Distribution of topics of all 1993 to 2019 ITFCSSR articles according to the journal (ITF, 2020).

ITFCSSR had more articles (209) than the JMST (101) indexed in GS. The greater coverage (44\%) of coaching/teaching by ITFCSSR is a strength of the journal that compliments the lower coverage (8\%) of this topic by JMST. ITFCSSR also had many indexed articles on tennis analytics and physiology (Figure 1). Similar to a recent report JMST indexed articles in GS (Knudson \& Myers, 2020), the distribution of topics of ITFCSSSR indexed articles did not appear to change over time (Figure 2). JMST, however, had qualitatively higher percentages of articles in sports medicine (13\%) than ITFCSSR $(2 \%)$. The current results also indicate a potential need for more tennis research in the area of nutrition $(0 \%)$ and equipment. Only $1 \%$ of indexed articles in ITFCSSR and $5 \%$ in JMST were on equipment (balls, courts, rackets, shoes) even though it has a significant influence on players and the sport.

The limitations of the study were related to the subjectivity of GS academic search engine, manual counting, cleaning, and classification of the results. GS has been criticized for lack of control of publications monitored, lack of time-control, limited text access, and search control features (Schultz, 2007; Pitsouni, \& Malietzis, 2008). This search engine, however, better coverage than publisher-driven, subscription (Walters, 2009). The major bibliometric databases like Web of Science are biased against small, specialized journals do not index. The labor-intensive and subjective process of cleaning errors in GS records, however, is also a limitation of 
bibliometric database research (Knudson, 2019). The of several results of this study with previous studies of GS in tennis science (Knudson, 2012; Knudson \& Myers, 2020), however indicate these limitations do not seriously affect the accuracy of the data or the inferences made.

\section{CONCLUSION}

It was concluded that ITFCSSR articles indexed in GS had relatively low citation rates that confirmed previous bibliometric research on the gradual development of tennis scientific knowledge compared to faster moving biomedical fields. ITFCSSR articles may make unique contributions to knowledge development in tennis, particularly in coaching, physiology, and analytics/tactics.

Disclosure: In accordance with my ethical obligation as a researcher, I have previously published in the journal under study that may be affected by the research in this report.
RECOMMENDED ITF TENNIS ACADEMY CONTENT (CLICK BELOW)

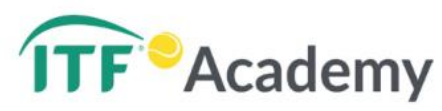

Copyright (c) 2020 Duane Knudson

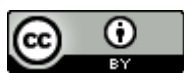

This text is under a Creative Commons BY 4.0 license

You are free to Share - copy and redistribute the material in any medium or format - and Adapt the content - remix, transform, and build upon the material for any purpose, even commercially under the following terms:

Attribution: You must give appropriate credit, provide a link to the license, and indicate if changes were made. You may do so in any reasonable manner, but not in any way that suggests the licensor endorses you or your use.

\section{REFERENCES}

Crespo, M., \& Over, S. (2010). ITF Coaching and Sport Science Review: A analysis of 17 years -50 issues. ITF Coaching and Sport Science Review, 50(18) 32-33.

Delgado-Lopez-Cozar, E. \& Cabezas-Clavjo, A. (2013). Ranking journals: Could google scholar metrics be an alternative to journal citation reports and scimago journal rank? Learned Publishing, 26, 101-114, https://doi.org/10.1087/20130206

Falagas, M. E., Pitsouni, E. I., Malietzis, G. A., \& Pappas, G. (2008). FASEB Journal, 22, 338-342, https://doi.org/10.1096/fj.07-9492LSF

ITF (2020). ITF CSSR Article List Full. https://www.itfacademy.com/?view=itfview\&academy=103\&itemid=1 $\underline{168}$

Knudson, D. (2012). Citation classics in tennis medicine and science. Journal of Medicine \& Science in Tennis, 17, 118-122.

Knudson, D. (2019). Judicious use of bibliometrics to supplement peer evaluations of research in kinesiology. Kinesiology Review, 8, 100-109, https://doi.org/10.1123/kr.2017-0046

Knudson, D., \& Myers, N. L. (2020). A bibliometric analysis of the Journal of Medicine \& Science in Tennis. Journal of Medicine \& Science in Tennis, Article in review.

Postma, E. (2007). Inflated impact factors? The true impact of evolutionary papers in non-evolutionary journals. PLoS One, 2(10), e999. https://doi.org/10.1371/journal.pone.0000999

Schultz, M. (2007). Comparing test searchers in PubMed and Google Scholar. Journal of the Medical Library Association, 95, 442-445, https://doi.org/10.3163/1536-5050.95.4.442

Velasco, J. V., \& Garcia, J. P. F. (2015). Review of sport science research specialized on wheelchair tennis. ITF Coaching \& Sport Science Review, 65(23), 14-15.

Walters, W. H. (2009). Google scholar search performance: Comparative recall and precision. Libraries and the Academy, 9, 5-24, https://doi.org/10.1353/pla.0.0034

Yuhuan, L. (2016). Bibliometric analysis of the sport core periodicals scientific literature of tennis research in recent ten years. Contemporary Sports Technology, 14, 159-160. 